\title{
The mechanical properties of an aluminum alloy by plasma-based ion implantation and solution-aging treatment
}

\author{
Zaiji Zhan ${ }^{\mathrm{a}, \mathrm{b}, *}$, Xinxin $\mathrm{Ma}^{\mathrm{b}}$, Yue Sun ${ }^{\mathrm{b}}$, Lifang Xia ${ }^{\mathrm{b}}$, Qiuyun $\mathrm{Liu}^{\mathrm{c}}$ \\ ${ }^{\mathrm{a}}$ Institute of Physics, Chinese Academy of Sciences, Beijing 100080, PR China \\ ${ }^{\mathrm{b}}$ School of Materials Science and Engineering, Harbin Institute of Technology, Harbin 150001, PR China \\ ${ }^{\mathrm{c}}$ State Key Lab for Non-linear Mechanics, Institute of Mechanics, Chinese Academy of Sciences, Beijing 100080, PR China
}

\begin{abstract}
The age-strengthening 2024 aluminum alloy was modified by a combination of plasma-based ion implantation (PBII) and solution-aging treatments. The depth profiles of the implanted layer were investigated by X-ray photoelectron spectroscopy (XPS). The structure was studied by glancing angle X-ray diffraction (GXRD). The variation of microhardness with the indenting depth was measured by a nanoindenter. The wear test was carried on with a pin-on-disk wear tester. The results revealed that when the aluminum alloys were implanted with nitrogen at the solution temperature, then quenched in the vacuum chamber followed by an artificial aging treatment for an appropriate time, the amount of AIN precipitates by the combined treatment were more than that of the specimen implanted at ambient temperature. Optimum surface mechanical properties were obtained. The surface hardness was increased and the weight loss in a wear test decreased too. (c) 2000 Published by Elsevier Science S.A. All rights reserved.
\end{abstract}

Keywords: Plasma-based ion implantation; Solution-aging treatment; Aluminum alloys; Mechanical property

\section{Introduction}

Apart from the conventional ion implantation technique, the PBII method is of increasing importance due to several advantages such as the homogeneity of implantation for targets with complex geometry [1]. In addition, many specimens can be implanted at the same time making it a cost-effective approach for the surface modification. Therefore, it seems appropriate to apply this promising technique to improve the surface properties in industry.

Nitrogen implanting into aluminum has been widely investigated in the past few years because of its potential industrial applications [2-4]. Since the solubility of nitrogen in aluminum is very low, and the reactivity of nitrogen with aluminum is high, formation of an AlN

\footnotetext{
* Corresponding author. Tel.: +86-10-82649146; fax: +86-1082649531.

E-mail address: 503g@aphy.iphy.ac.cn (Z. Zhan).
}

precipitate is favored [5-7]. The surface modification of aluminum alloys by ion implantation offers the possibility of widely using aluminum in applications with a combination of high wear resistance and low weight [8-10]. Up to now, the phenomenon and its consequences on the mechanical properties of pure aluminum have been extensively studied, but the effect on surface structure, hardness and wear resistance of aluminum alloys must be investigated further. It is well known that the surface mechanical properties are mainly influenced by the implanted layer, but the matrix is another important factor too. The 2024 aluminum alloy is a typical age-strengthening alloy. By combining the solution treatment of aluminum alloy with PBII treatment, the surface layer and its matrix can be strengthened at the same time. The aim of this work was to study the mechanical properties of the combined treatment on 2024 aluminum alloy. The results presented in this paper suggested a new approach to the PBII treatment of aluminum alloys in general. 


\section{Experiment details}

The 2024 aluminum alloy specimens were carefully ground with $\mathrm{SiC}$ abrasive papers and polished with diamond paste to a grit size of $0.25 \mu \mathrm{m}$, and then cleaned ultrasonically before ion implantation. The ion implantation experiment was carried out on a DLZ-01 plasma-based ion implanter at Harbin Institute of Technology. Firstly, the specimens were biased by a negative voltage pulse of $60 \mathrm{kV}$ with a pulse duration of $45 \mu \mathrm{s}$ and a repetition rate of $100 \mathrm{~Hz}$ for $3 \mathrm{~h}$. The specimens were kept at $500^{\circ} \mathrm{C}$ (the solution temperature of 2024 aluminum alloy) during ion implantation, and this process resulted in a retained dose $6 \times 10^{17}$ $\mathrm{N}^{+} \mathrm{cm}^{-2}$. The residual vacuum in the implantation chamber was $1 \times 10^{-4} \mathrm{~Pa}$, and the working vacuum was $3 \times 10^{-2} \mathrm{~Pa}$. When the implantation was finished, all the specimens were pushed into oil to quench immediately by a manipulator in the vacuum chamber. Finally specimens were aged for $10 \mathrm{~h}$ at $170^{\circ} \mathrm{C}$ to reach the peak-age in a vacuum furnace. As a reference, a specimen was only implanted at ambient temperature to $6 \times 10^{17} \mathrm{~N}^{+} \mathrm{cm}^{-2}$.

The depth profiles were measured by XPS (PHI ESCA 5700) with $\mathrm{Mg} \mathrm{K} \alpha(1253.6 \mathrm{eV})$ radiation. A high vacuum of $10^{-6} \mathrm{~Pa}$ was maintained throughout the measurement. The $\mathrm{Ar}^{+}$ion beam of $3 \mathrm{keV}$ and $30 \mu \mathrm{A}$ was used for depth profiling. For the depth profiling, time was varied keeping a constant current $(30 \mu \mathrm{A})$. The sputtering rate was approximately $3.5 \mathrm{~nm} \mathrm{~min}{ }^{-1}$.

The phases present in the modified layer were determined by GXRD (D/max-rB X-ray diffractmeter) with $\mathrm{Cr} \mathrm{K} \alpha$ radiation, vanadium filter at voltage $30 \mathrm{kV}$, current $80 \mathrm{~mA}$, glancing angle $1^{\circ}$, step-scanning mode (step $0.01^{\circ}$, speed $4 \mathrm{~s} \mathrm{step}^{-1}$ ).

The variations of microhardness with the indenting depth were measured on the Nano Indenter ${ }^{\mathrm{TM}}$ II. The wear test was carried out with a pin-on-disk wear tester. The specimens implanted with nitrogen were used as the disk and a 5-mm diameter cylinder 52100 bearing steel with a hardness of HRC63 was used for the pin. The wear test was unlubricated, used a $5-\mathrm{N}$ load, the sliding speed of $180 \mathrm{~mm} \mathrm{~s}^{-1}$, and wear time was $10 \mathrm{~min}$ at ambient environment (room temperature $20^{\circ} \mathrm{C}$, humidity $25-30 \%$ ).

\section{Results and discussion}

\subsection{Depth profiles}

Fig. 1 shows the depth profiles of 2024 aluminum alloy measured by XPS. The content of nitrogen in the aluminum matrix presents a Gaussian-like distribution with a peak (atomic concentration of $30 \%$ ) at approximately $105 \mathrm{~nm}$ from the outer surface, and the maxi-

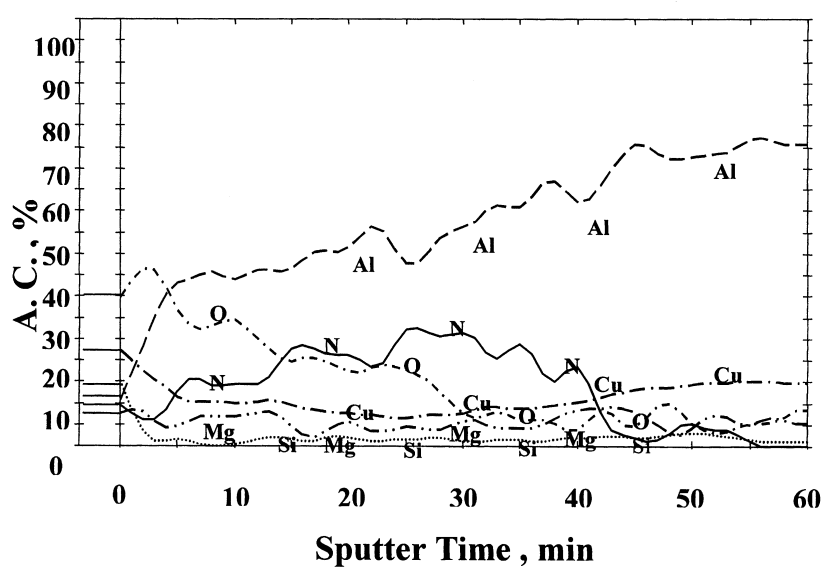

Fig. 1. XPS depth profiles of 2024 aluminum alloy implanted with $6 \times 10^{17} \mathrm{~N}^{+} \mathrm{cm}^{-2}$ at $60 \mathrm{kV}$.

mum thickness of the implanted layer is approximately $175 \mathrm{~nm}$. It is well-known that the solution of nitrogen in aluminum is very low (from 0.0002 to $0.001 \%$ in solid), so after ion implantation, not only is there a fine dispersion of AlN precipitates but also a supersaturated solid solution of nitrogen is formed. These effects increased the surface hardness of the aluminum matrix $[6,8]$. The solid solution of nitrogen may be another strengthening mechanism of the surface layer [10].

\subsection{Structure}

The direct evidence indicating the formation of the AlN precipitate was obtained by GXRD studies (incident angle of $1^{\circ}$ ). Fig. 2 shows the XRD patterns of a 2024 aluminum alloy surface implanted with $\mathrm{N}^{+}$. The diffraction peaks of AlN appeared at $2 \theta=50.3^{\circ}, 54.8^{\circ}$ and $57.7^{\circ}$, respectively. The corresponding $D$-values were $0.271,0.250$ and $0.238 \mathrm{~nm}$, respectively. These $D$-values agreed well with the (100), (002) and (101)

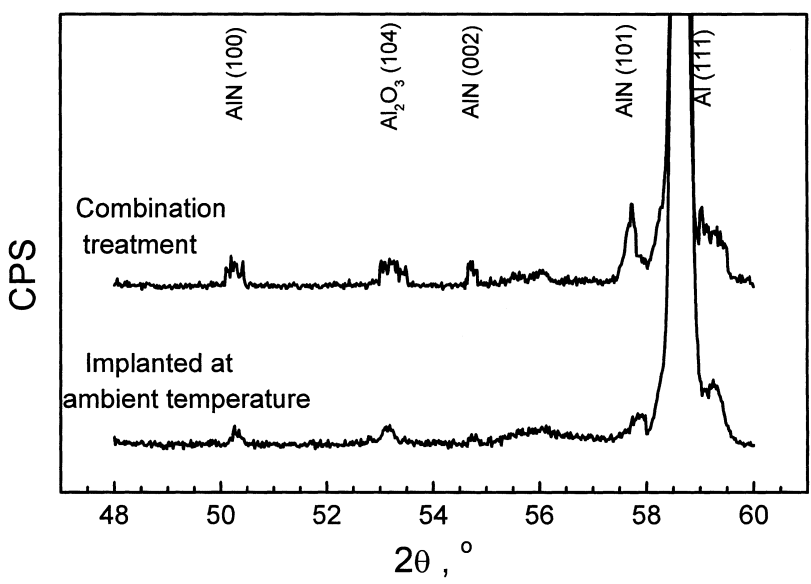

Fig. 2. Glancing angle X-ray diffraction of 2024 aluminum alloy implanted with nitrogen ions to $6 \times 10^{17} \mathrm{~cm}^{-2}$ at different implantation temperatures at glancing angle $1^{\circ}$. 


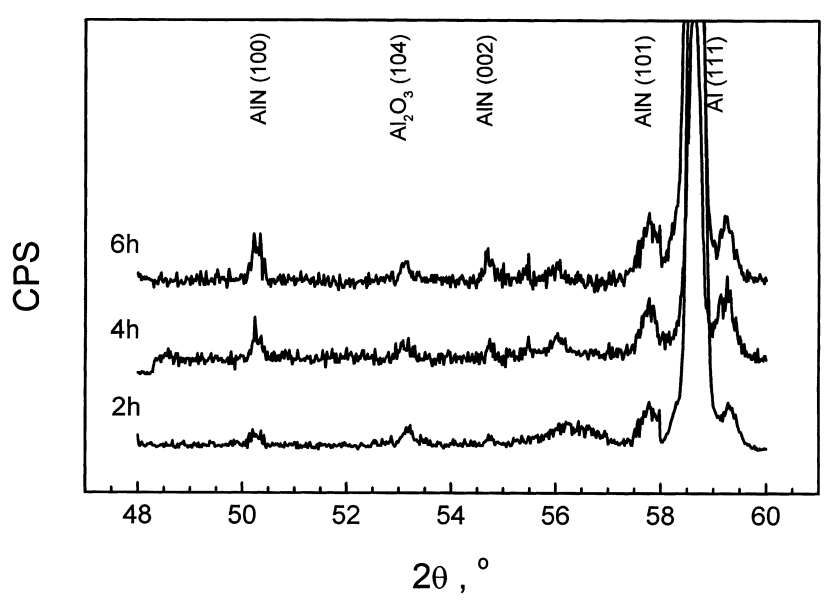

Fig. 3. Glancing angle X-ray diffraction of the specimen implanted with nitrogen ions and annealed at $400^{\circ} \mathrm{C}$ for different time at glancing angle $1^{\circ}$.

planes of AlN crystal with a $h c p$ structure, compared with the ASTM card.

Fig. 2 also shows that after the combined treatment (implanted at solution temperature, then artificial aging), the amount of AlN precipitates were more than that of the specimen only implanted at ambient temperature. The higher implantation temperature was advantageous to form AlN precipitates [11], in agreement with other researchers [12]. In addition, the formation of AlN precipitates was favored by prolonging the annealing time after ion implantation [13] (as shown in Fig. 3).

\subsection{Microhardness}

Nanohardness results are shown in Fig. 4a. The nanohardness of unimplanted regions shows a slight peak at the surface and reaches a plateau close to aluminum alloy hardness (1.2 GPa). This peak is probably a combination of both the real effect of native oxide at the surface or an effect of the polishing procedure, and an artefact of the shape indenter tip for small indents. The nanohardness measured inside the implanted area showed a broad peak with a maximum in the vicinity of $80 \mathrm{~nm}$ and an FWHM of approximately $200 \mathrm{~nm}$. It was clear that the maximum surface hardness of the specimen (approx. 9.8 GPa) obtained by the combined treatment is higher than that of the specimen (approx. $8 \mathrm{GPa}$ ) only implanted at ambient temperature.

The calculated results of the elasticity module are shown in Fig. 4b, also indicating that in the implanted layer, the elasticity module of the specimen obtained by the combined treatment $(190 \mathrm{GPa})$ is higher than that of the specimen by normal implantation $(162 \mathrm{GPa})$.

\subsection{Wear test}

It is important to note that, nitrogen ion implantation is used to convert the surface of aluminum alloys to a thin, continuous surface layer of AlN precipitates. Since AIN is a ceramic material with different properties from metals, different wear behavior is observed. The implanted layer $(0.2 \mu \mathrm{m})$ is thinner than the contact diameter $(10-150 \mu \mathrm{m})$ between the specimen and the wear disk. Therefore, the wear behavior is determined by a combination of the mechanical properties of the implanted layer and the matrix.

Fig. 5 shows the relationship between the weight loss in a wear test and the implantation parameter. It reveals that after the wear test, the weight loss of the specimen obtained by combined treatment is approximately $0.15 \pm 0.02 \mathrm{mg}$, it is lower than that of the specimen implanted at ambient temperature (approx. $0.19 \pm 0.02 \mathrm{mg}$ ).
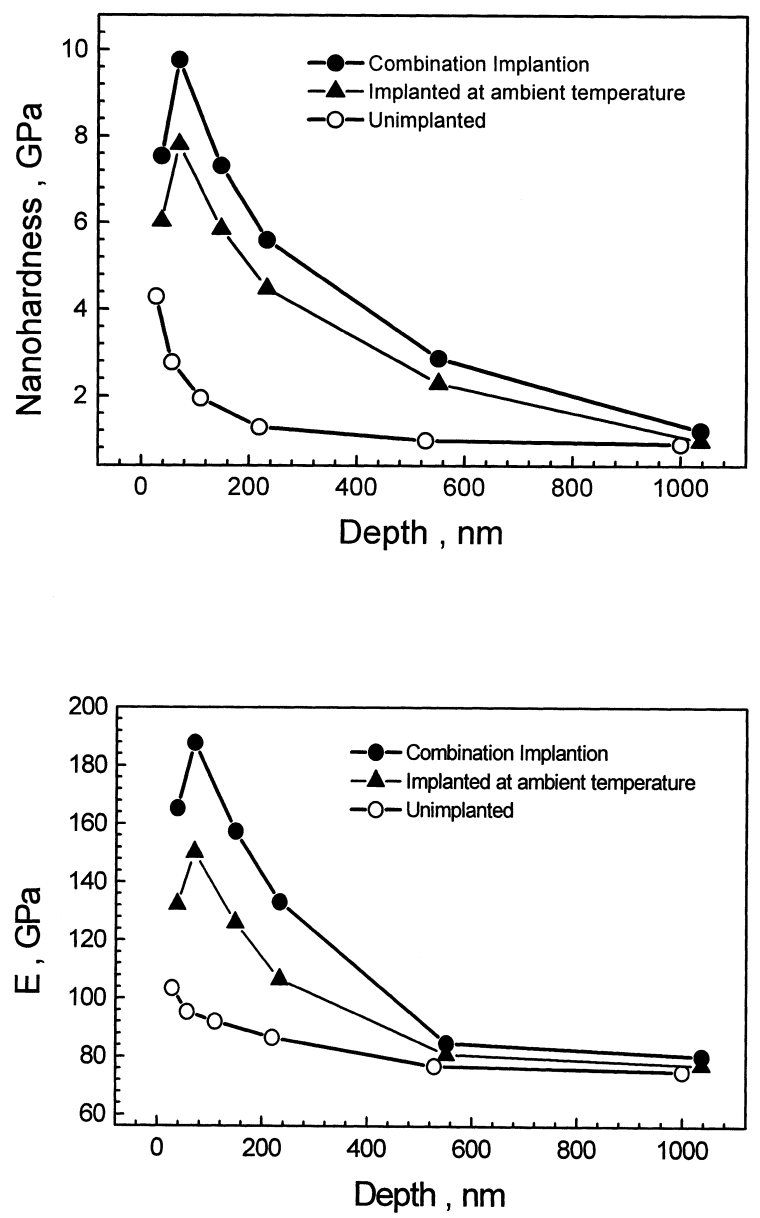

Fig. 4. Variation of nanohardness, elasticity module with the penetrating depth $\left(6 \times 10^{17} \mathrm{~N}^{+} / \mathrm{cm}^{2}\right)$. (a) The relationship between nanohardness and penetrating depth. (b) The relationship between elasticity module and penetrating depth. 


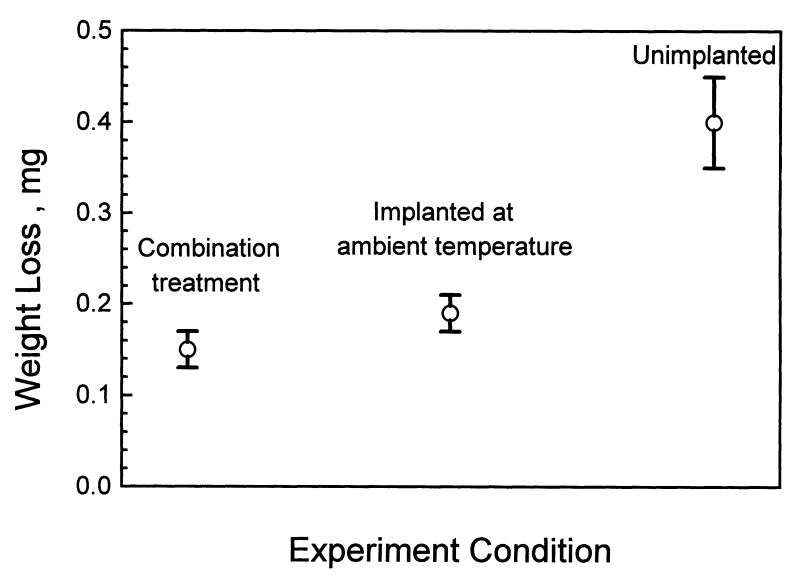

Fig. 5. Variation of weight loss in a wear test of 2024 aluminum alloy with the implantation condition.

It is clear that optimum mechanical properties could be attained by the combined implantation PBII and solution-aging treatment.

\section{Conclusion}

The age-strengthening 2024 aluminum alloy was modified by the combination of plasma-based ion implantation and solution-aging treatments. The depth profiles of the implanted layer were investigated by XPS. The surface structure was studied by GXRD. The variations of microhardness with the indenting depth were measured by a nanoindenter. The wear test was carried out on a pin-on-disk wear tester. The results revealed that when the aluminum alloys were implanted with nitrogen at the solution temperature, then quenched in the vacuum chamber followed by an arti- ficial aging treatment for appropriate time, the amount of AlN precipitates by the combined treatment were more than that of the specimen only implanted at ambient temperature. Optimum surface mechanical properties were obtained; the surface hardness was increased and the weight loss in the wear test decreased too.

\section{Acknowledgements}

This work was supported by the National Science Foundation of China (NSFC NO. 59771059).

\section{References}

[1] J.R. Conrad, US Patent, No.4764394, 1988-08-16.

[2] R. Gunzel, E. Wieser, E. Richer, J. Vac. Sci. Technol. B 12 (1994) 927-930.

[3] K.C. Walter, J. Vac. Sci. Technol. B 12 (1994) 945-950.

[4] S. Lucas, J. Chevallier, N.G. Chechenin, Surf. Coat. Technol. 66 (1994) 334-338.

[5] L. Guzman, G. Bonini, M. Adami et al., Surf. Coat. Technol. 83 (1994) 284-289.

[6] L. Xia, R. Wang, X. Ma, J. Vac. Sci. Technol. B 12 (1994) 931-934.

[7] Z. Zhan, X. Ma, L. Xia, Chin. J. Mater. Res. 12 (1998) 546-548.

[8] F.A. Smidt, G.K. Hubleeer, Nucl. Instrum. Meth. B80/81 (1993) 207-212.

[9] X.Y. Li, K.N. Tandon, Surf. Coat. Technol. 90 (1997) 136-142.

[10] Z. Zhan, X. Ma, L. Feng, Y. Sun, L. Xia, Wear 220 (1998) $161-167$

[11] Z. Zhan, X. Ma, L. Xia, The Fourth International Plasma-Based Ion Implantation Workshop, Dearborn, Michigan, USA, June 2-4, 1998.

[12] C. Blawert, B.L. Mordike, Nucl. Instrum. Meth. 127/127 (1997) 873-878.

[13] Z. Zhan, Ph.D thesis, Harbin Institute of Technology, 1999 p.91. 